\title{
Energy Justice in Apartment Buildings and the Spatial Scale of Energy Sustainable Design Regulations in Australia and the UK
}

\author{
Alexa Gower* \\ Department of Urban Planning and Design, Monash University, Melbourne, VIC, Australia
}

\section{OPEN ACCESS}

Edited by:

Edgar Liu,

University of New South

Wales, Australia

Reviewed by:

Sujit Sikder,

Leibniz Institute for Ecological Urban and Regional Development

(IOER), Germany

Emma Elizabeth Heffernan,

University of Wollongong, Australia

*Correspondence: Alexa Gower

alexa.gower@monash.edu

Specialty section: This article was submitted to Urban Energy End-Use, a section of the journal

Frontiers in Sustainable Cities

Received: 21 December 2020 Accepted: 21 April 2021

Published: 25 May 2021

Citation:

Gower A (2021) Energy Justice in Apartment Buildings and the Spatial Scale of Energy Sustainable Design Regulations in Australia and the UK. Front. Sustain. Cities 3:644418. doi: $10.3389 /$ frsc. 2021.644418
Energy vulnerability is a growing concern in many OECD countries post-millennium. An increasing number of residents go without heating or cooling necessities to manage the financial strains of increasing energy costs, low wage growth, and rising housing costs. Housing design quality contributes significantly to a dwelling's energy use and the resident's potential energy vulnerability with good orientation enabling passive climate control or, alternatively, poor design resulting in a reliance on artificial heating, cooling, and lighting for livability. Housing design regulations are accepted as an important tool in planning for achieving energy sustainability and mitigating climate change. However, this article argues for greater recognition and knowledge regarding regulation's ability to protect against energy vulnerability at the residential scale, particularly in the growing number of apartments purchased for the rental market in Australia. By observing the energy sustainability of apartments deemed permissible by Australian and UK regulations, this research demonstrates the significance of building scale in regulations when applied to apartments buildings. An energy justice lens reveals a distinction between measurement at the whole building level and the individual apartment/resident scale in this building typology in particular.

Keywords: energy justice, apartment (residential building), design regulation, energy vulnerability, housing

\section{INTRODUCTION}

Energy vulnerability describes residents at risk of being unable to reasonably afford energy consumption for their dwelling (Daniel et al., 2020). For those with low incomes, residential energy costs can be a high proportion of their available income. This cost places significant financial strain on the household, mainly when a rise in energy use occurs during a heatwave or longer than expected winter. Managing this financial precarity is difficult, especially when the resident has little alternative means to buffer these fluctuations. As a result, many energy vulnerable residents tightly restrict or reduce their energy consumption to the bare minimum.

This restriction or reduction of energy use for energy vulnerable residents can have significant health and well-being implications. While there are sustainability arguments for being mindful of energy use and requirements, in contrast, energy vulnerable residents forego basic living necessities to manage or reduce their expenditure only (Azpitarte et al., 2015; Thomson et al., 2017). They go without basic comfort levels: enduring sleepless nights in hot dwellings or foregoing winter heating, which can lead to an increased risk of respiratory-related illness from damp and mould growth 
(Giles-Corti et al., 2015). This denial of a level of essential comfort also contributed to mental health issues as energy vulnerable residents struggle without these necessities and are conscious of this absence comparatively in their lives (Liddell and Guiney, 2015). Energy justice is a lens that highlights the inequity in energy vulnerability by proposing that energy is an accessibility right and that necessities should be available to everyone, irrespective of affordability (McCauley, 2018).

As well as rising energy costs (Potter and Tillet, 2017), there are common trends, both internationally and in Australia, of people managing additional financial strain from rising housing costs and low wage growth (Parkinson et al., 2019). Australia, for example, has experienced an average 5\% nominal increase in annual house prices from 2005 to 2015 (Kohler and Van Der Merwe, 2015), the UK a $7 \%$ and London a $14 \%$ increase (Land Registry, 2020). This rise has occurred disproportionately to wage growth alongside increasingly high unemployment rates (ABS, 2017a; Bagshaw, 2018). During 2020, many households also had to manage pandemic related periods of reduced or an inability to work due to city lockdowns (Hutchens, 2020). To manage an affordable living, since 2006, there has been a $4 \%$ rise in the renting population of Australia (Australian Bureau of Statistics, 2016a) and a 14\% shift in the rental housing type towards the relatively more affordable apartment buildings Australia wide (Australian Bureau of Statistics, 2016b). With this growth of the apartment typology as rental properties in Australia, it is essential to note that energy sustainable design is lower quality in rental properties and apartment buildings are particularly poor quality within the Australian rental building stock. Recent studies have documented rental apartments with a relatively high reliance on artificial heating and cooling and limited passive design measures (Australian Council of Social Services, 2017; Baker et al., 2018; Poruschi and Ambrey, 2018; Easthope et al., 2020).

This research examines energy vulnerability in apartments and how housing design regulation, focusing on passive energy design, can help alleviate energy vulnerability in apartments through the building scale at which compliance is defined. Scale, in this instance, is defined as the apartment building as a whole vs. the resident scale of each individual apartment dwelling within this building. The growing significance of the issue of energy poverty in Australia, particularly for residents in rental properties (Daniel et al., 2021), is beginning to be fully recognised by government planners and policymakers. In 2020, new requirements were introduced for efficient heating and cooling technology in rental properties and targeted financial subsidies for energy costs as a way to offset these pressures (D'Ambrosio, 2020). Given this recent recognition of the significance of the issue, it is crucial to examine further the contribution passive energy design can offer residents and how regulations around this can proactively alleviate energy vulnerability by reducing the requirement on artificial heating and cooling technologies.

Energy sustainability impacts various groups, with the impact of the built environment on climate change a commonly cited focus (Sovacool et al., 2014). Energy justice additionally recognises the importance of the scale of the resident experience in energy sustainability. The resident scale is significant as Henning (2020) argues that the impact of energy sustainability as energy vulnerability is unequally experienced at the resident scale. This article argues the significance of scale in energy sustainable regulations for apartment buildings particularly as an energy justice lens reveals a distinction between measurement at the whole building level and the resident scale in this building typology. This research finds that the Australian national housing design regulation approaches energy sustainability from the whole building scale and ensures that new buildings overall do not impede the city from meeting agreed climate change emission targets. This entire building scale incorporates energy sustainability protection for the resident in detached housing, but it does not appreciate the distinctions of scale in an apartment building. An apartment building comprises multiple individual apartments that can differ in performance to each other as long as the aggregate meets the regulation when measured on the whole building scale. This aggregate level of energy sustainability in regulation is essential as a positive step towards mitigating climate change. Still, it offers limited energy vulnerability protection to residents of apartments as differences in energy performance can occur between individual apartments in the same building. This unequal distribution of performance is particularly significant as this research found, that studio and 1-bedroom apartments, predominantly rental properties (ABS, 2018), are primarily building's poor performing ones. This article expands on the significance of this scale in energy sustainability regulations, particularly with the apartment building typology's growth in the Australian rental market.

This research examines the case study of energy sustainability in housing design regulations through the Australian National Construction Code Vol. One (NCC) (Australian Building Codes Board, 2019) foremost with contrast to London's Housing Supplementary Planning Guide (LHSPG) (Mayor of London, 2016). It investigates this by observing what design trends remain permissible by each regulation and the standard apartment market practises occurring in the buildings. This article first discusses the significance of the issue and follows with a review of the literature on housing design regulations in apartment and energy justice. It then outlines the methods used, results obtained, and a discussion on the significance of scale in regulations to address energy justice issues in apartment buildings.

\section{How Scale Currently Operates in Housing Design Regulations}

Energy vulnerability is an increasing issue in many OECD countries since the early 2000's due to rising energy costs internationally. The number of energy vulnerable residents is becoming increasingly prevalent in Australia, more so than in other countries. One in four Australian households is currently at risk of being unable to pay their energy bills or forego essential daily energy use (Azpitarte et al., 2015). A contributing factor to this increase is the relatively high energy costs in Australia compared to international rates. Australian states have some of the highest individual prices compared with the US and EU countries (IEA, 2015; Potter and Tillet, 2017). The state of South Australian prices were nearly $300 \%$ more than the US rates, closely followed by the Australian states of NSW, Queensland and 
Victoria at the fourth, fifth and sixth highest rates in Potter and Tillet's study.

While energy vulnerability is the problem that many residents face, housing design and regulations offer a solution to this problem by seeking to improve the design's energy sustainability. The role of good housing design in alleviating energy use and reliance for heating, cooling and lighting has been wellrecognised in practise and academia (Poor et al., 2018). Good design manages the sunlight exposure and accompanying radiant heat inside the dwelling to enable it to stay at a comfortable temperature without the use of artificial heating or cooling. Orientation is one significant design method for passively controlling sunlight exposure with the careful management of the design layout of the dwelling related to the exposure of the sun. Design that is mindful of this can carefully control the internal room temperature to be more moderate in summer and receive passive heating during winter. Conversely, poor orientation can contribute to the reliance of the dwelling on artificial heating, cooling and lighting due to the extremes of temperature and light levels that the dwelling is exposed to. Poor design, therefore, significantly impacts the energy used by the resident as they attempt to make the dwelling habitable. While improvements in heating and cooling technology are important to alleviating some of the stress of energy vulnerability (Pears, 2020), the impact of this improvement is limited if the dwelling design is poor and requires regular reliance on artificial heating and cooling.

Housing design regulations are a widely adopted tool to guide housing design in both planning and construction needs. They operate by assisting the evaluation of the design of a project and whether this design meets the minimum deemed acceptable (Tiesdall and Allmendinger, 2008). Good housing design, including orientation, is generally uncontroversial among development practitioners (Moore et al., 2014). However, achieving it within the building design is also acknowledged as complex due to the multiple contributing and interconnecting components in the housing product that are often in competition with one another (Berry, 2014). This interconnection and incompatibility of components directly complicate the building's design and forces prioritisations or trade-offs to be made between different components such as the aesthetics of design, cost and amenity in the project. Housing design regulations are a tool to ensure that the necessities of health, safety and amenity are met with these trade-offs occurring in the project (Freestone, 2012).

Planning regulations specifically stipulate requirements for those indirectly affected, the externalities, by the project. Externalities are people, such as neighbours, members of the public and future citizens impacted by the proposed building design but do not have a direct voice in its form or construction through direct or financial involvement in the project (Freestone, 2012). Climate Justice and energy sustainability acknowledge the indirect impact of the built environment on climate change as an externality. Climate Justice highlights distant examples of the environment, populations disproportionately affected by the consequences of climate change such as coastal city flooding due to increased seawater levels, and future generations who will need to manage a world affected by climate change (Sovacool et al., 2014). Planning regulations typically acknowledge these externalities and therefore stipulate that new buildings mitigate or positively reduce their effects on climate change by ensuring that the overall building is energy sustainable on the whole.

Research on climate change design regulations has highlighted the relatively low requirements in Australian regulations compared to international stipulations (Moore and Holdsworth, 2019) and the need for international standardisation in requirements if regulations are to mitigate the global issue of climate change (Horne, 2006). Rickwood et al. (2008) also note the need for further research on energy use contribution to emissions, including in densely built environments. These articles focus on building regulation requirements for mitigating climate change generally. Two studies: Heffernan et al. (2017) and a scoping report for new apartment regulations in Victoria, Australia (ARK resources, 2016), both focus instead on the application of the regulations in apartment buildings. As a result of this focus, they both reveal flaws in the regulations that lower the requirements when applied in the apartment building type. The scoping report, in particular, investigates the same NCC regulation as this research and highlights how the apartment building form impacts the efficacy of the regulation. It explains that the shared concrete walls, ceiling and floor that typically occur in an apartment but are less prevalent in a detached house, traps the heat gained by sun exposure from the full height glazing at the front. Compared to a detached house, this lowers the apartment dwelling's heating requirements in winter but leads to significantly high cooling needs in summer. The report highlights that the NCC does not capture the extremity of seasonal difference in apartments as it sums both requirements into an overall energy efficiency score. This aggregation permits apartments to perform at a worse energy efficiency rate in summer than is allowable in a detached house by the same regulation. This literature highlights the need for further understanding of regulation performance in apartment buildings precisely and how this particular building form can negatively impact the already low energy sustainability levels required by the regulation. Although housing design regulations for climate change are standard, in market-based property economies, the intervention of planning regulations to the resident's experience of the internal space as a home is generally avoided and argued against via the logic of the market (Simmons, 2008). Through this logic, building scale is introduced into the design regulation. Regulation compliance can be defined at either the whole building overall as occurs for regulations for climate change or at the individual apartment within the overall building by recognising that an apartment building is composed of multiple apartment dwellings with individual residents having different experiences. Market logic proposes that if one assumes the apartment market functions well, the explanation for poor design is that it is simply a result of the market responding to and only providing what is desired or chosen by the homebuyer. Regulations are therefore not valid at this scale. This explanation's central idea is that apartment quality is assured through the purchaser who buys the apartment. This logic, however, breaks down with the multiple complexities of the apartment housing product and its role within the housing market (Simmons, 2008). Consumers are unpracticed in evaluating design due to the 
infrequency of purchasing a home (Marsh and Gibb, 2011). This is further complicated by the unfamiliarity of living in apartments in Australia and the "off-the-plan" before construction method of sale of apartments (Dow, 2015).

The most significant contributing factor is the prevalence of apartments as investment properties for the rental market. Apartment purchases in Melbourne have been recently dominated by investors, with the 2016 census finding that $67 \%$ of apartments in the Greater Melbourne area were private rental accommodation and only 68,123 out of 207,408 apartments as owner-occupied (ABS, 2017b). Investment properties disconnect the apartment user-the renter-from the apartment producer (Carmona et al., 2010). The purchaser, the individual with the power to choose the apartment's qualities, is a landlord who may never directly experience the space as a home. Instead, the qualities that they perceive as necessary relate to financial gain possible in the purchase of the property, known as split incentives, rather than those that contribute to the dwelling's livability (Prasad, 2004). Liu and Judd (2018) explain that the rental sector's split incentives mean that the renting resident rather than the homeowner is responsible for paying for the energy usage. Consequently, there is little incentive for investors to prioritise energy design quality especially if they are required to pay additional upfront for these benefits. Daniel et al. (2020) also concur that this perception of housing as a commodity in Australia, particularly regarding investment rental properties, creates barriers to energy efficiency improvements due to the perceived added upfront costs and lack of return on capital investment. The process of renting further disempowers the residents to select sustainable energy design in individual apartments. Melbourne's low rental vacancy rate reduces the choice and options for renters as they cannot refuse the low design quality offered (Hulse and Yates, 2016). There is also little prior disclosure of the property's energy efficiency in the rental application process, as this disclosure is voluntary (Moore and Holdsworth, 2019). Furthermore, the rental market's competition often discourages applicants from requesting further information for the risk of tarnishing their reputation as a "desirable" tenant. Together these market failures suggest an essential role for planning regulation to assist market delivery of the value of energy sustainable design quality in apartments as argued by Daniel et al. (2020) and recognise the apartment rental market as an externality (Berry, 2014).

Despite this justification for the intervention of planning regulation in the direct resident's experience of energy vulnerability in apartments, regulation at the resident scale remains controversial among practitioners (Glossop, 2015). It is argued that direct resident experience is a matter for construction regulations only as these regulations manage the minimum requirements for the health and occupational safety in the new build, mainly focusing on the resident directly affected in the project (Booth, 1996). However, Daniel et al. (2020) highlight that Australia' construction currently lack basic health protections related to energy vulnerability for the resident, despite health being a generally accepted topic for intervention for construction regulations (Glossop, 2015). Instead, when Australian construction regulations address energy sustainability issues, mitigating climate change via the whole building scale is again the focus, and the resident scale isn't addressed. This debate on the validity of planning regulation intervention alongside the inadequacy of energy vulnerability protection in apartments in construction regulations highlights the greater understanding needed on energy sustainability in apartment buildings. Further evidence is required on the role of planning regulations to protect the resident's experience in apartments, precisely rental properties, and the impact that regulation building scale has on providing sufficient protection against energy vulnerability. This research seeks to address this gap by observing building designs that have received planning permission to reveal the design practises in the apartment market that remain permissible by the current housing design regulations. These observations analyse the building's scale, whether at the whole building or the individual resident apartment level, that the regulations are applied at and corresponding industry trends.

Energy justice provides a lens to examine the scale of application in housing design regulations. It acknowledges the resident experience scale in energy vulnerability and justifies regulation intervention from a perspective of equity (Henning, 2020). In addition to energy sustainability being a global issue of climate change, energy justice research argues that the impact of energy sustainability is disproportionately felt at the individual scale in energy vulnerability. Consequently, there is a substantial body of energy justice literature on the resident's experience as a result.

Henning (2020) summarises energy justice to include research on how certain population groups have an increased risk of energy vulnerability, why this disproportion and patterns in risk levels occur, as well as resident practises and their implications when experiencing energy poverty. Research by Islar et al. (2017) investigates access to energy as part of a minimum level of well-being that all citizens should have and how this access forms a universal right. McCauley (2018) extended this by arguing for an accessibility approach to energy justice and not a focus on affordability and price as occurs in energy poverty research. Walker and Day (2012) also argue that this asks for a situated approach for justice that recognises that, in addition to equal access, some people need increased assistance to realise their fundamental rights leading to a role for policy and regulation. As a lens on the resident scale, energy justice is therefore used by this research to contribute an understanding of equity and justice in energy sustainability.

The resident scale of energy sustainable regulation raises equity issues when renters, as externalities, dominate a specific apartment size type in the whole building. Of the $67 \%$ apartments as rental properties in Greater Melbourne, rental properties represent a high proportion of the smaller apartment bedroom types. Renters occupy $91 \%$ of studios, $80 \%$ of 1 -bedroom but less than half of the 3-bedroom $(48 \%)$ and above (38\%) present (ABS, 2018). Without regulation protection at the resident scale, there is a significant risk of unequal distribution of poor performing apartments in these types prevalent as rentals with limited self-agency, as highlighted earlier. 
Despite this energy justice contribution to understanding justice in energy sustainability via the residents' experience, Simcock and Mullen (2016) note that the energy justice literature, to date, fails to incorporate fine-grain policy analysis related to these experiences. This research body lacks a connexion between the resident scale to the equity objectives in energy vulnerability policies and planning regulations on energy sustainability. Furthermore, Sovacool and Dworkin (2015) highlight how energy justice literature lack pragmatic recommendations on how values can be practically introduced to planning and housing design regulations to include equity within the energy sustainability issue. For housing design regulations to assist energy vulnerability in apartment buildings, there is a significant need for further research into energy justice at the individual apartment scale but with a clear focus on how regulations can practically implement justice. This article seeks to address this gap of pragmatic policy recommendations in energy justice knowledge by observing of the in-practise application of two different regulation approaches.

This article has, so far, highlighted crucial gaps in the understanding of the role of scale in design regulations on energy sustainability, with the whole building scale looking to mitigate climate change and the resident scale addressing energy vulnerability. Some progress has occurred in acknowledging the significance of energy vulnerability in Australia and ensuring minimum efficiency for heating and cooling technology in dwellings (D’Ambrosio, 2020). However, the benefits available through passive energy housing design and good orientation is a significant opportunity that is yet to be realised in regulation. Instead, it is argued that regulation should not intervene with the resident's experience of energy sustainability directly within the home as the resident can select what level of quality they deem as necessary (Simmons, 2008). However, this article notes the externality of renters within the apartment market. Housing design regulation that defines energy sustainability at the whole building level fails to protect the individual apartment resident within the building. Using an energy justice lens, this article highlights a gap in understanding the implications of scale in apartment regulations and their ability to acknowledge and alleviate energy vulnerability through design. It will do this through the research question; how definitions of scale in energy sustainability regulation operate in apartment buildings and the impact this has on the efficacy of regulations alleviating energy vulnerability? This article also seeks to contribute to the gaps in energy justice literature by focusing on pragmatic recommendations for policy improvement and application in regulation and design practise.

\section{RESEARCH DESIGN}

To investigate the research gaps identified above, case study research of housing design regulation was conducted. The different requirements for satisfactory energy sustainability housing design were explored in the two regulation approaches of Australia's National Construction Code Vol. One (NCC) (Australian Building Codes Board, 2019) and London's Housing Supplementary Planning Guide (LHSPG) (Mayor of London, 2016). These requirements in the regulations were empirically investigated through a spatial observation and assessment of the design of apartments built under these regulations. This spatial observation focused on Melbourne, Australia and London, UK, as two cities experiencing acute housing affordability problems alongside current apartment construction booms.

\section{Case Study Research}

Case study research can provide an in-depth understanding of an issue by examining not only the particular situation and its context but also critically engaging with the interactions and relationships between these elements (Yin, 2014). Case study research acknowledges that complex situations, such as housing design policy, cannot always clearly define or distinguish the boundaries between the phenomena and its context. Looking at the relationships and interactions between the housing energy sustainable design regulations and its context can provide a detailed account of the situation through which to better understand the issue, in this case, of design regulation's effectiveness.

Investigating the case study of housing energy sustainability regulations across two different sites enabled this research to understand the complexity of design regulations in achieving equity and environmental sustainability (Yin, 2014). This expansion of housing design regulations studied was not intended to produce a comparison between the two approaches or specify a more successful tool. Nor was the expansion planned to validate a particular theory through repetition. Instead, analysing what is not occurring in each place enables the researcher to appreciate the particulars of housing design regulation better and appreciate the breadth and complexity possible (Oxley, 2004, p. 190). Reviewing differences and similarities furthered the understanding of the topic, more so than any critical evaluation of a city's design regulation or validation of the theory through replication.

From a systematic review, the two countries of Australia and the UK were selected for their legal framework similarity: a case law system. This framework structures each country's approach to values and regulations. Australia first undertook developing technical building codes in the early 1970s, the National Construction Code (NCC) and introduced a designated environmental sustainability section J in 2000 (ABCB, 2020). The NCC is a statutory regulation that applies to all building types, including detached and apartment buildings, consistently across Australia. Still, as mentioned earlier, the regulations are applied at the whole building level, and the code does not recognise each apartment within the whole apartment building. While New South Wales, Australia, has introduced the SEPP 65 and the Apartment Design Guide to address this regulation gap at the individual apartment scale, this regulation only applies to builds within a select region of Australia. This additional regulation level is discretionary to each Australian state government planning department and has not been introduced in all states of Australia. In Melbourne, Australia, there has 
recently been a rapid increase in the growth in apartment planning approvals and construction (ABS, 2019; Department of Environment Land Water Planning, 2015). This apartment development was orientated, particularly towards private rental, with Melbourne becoming both an Australian and world leader in apartment development for investment (CoreLogic, 2016; ABS, 2017b). Melbourne's burgeoning apartment design and construction period occurred with only the NCC for design guidance, with specific apartment planning design regulations that include energy requirements not introduced by the Victorian government in 2016 (2016, 2016). The UK, by comparison, has a long history of government intervention specifically into apartment design quality, including internal design. Both London and the UK regulators have experimented with different forms of sustainable design intervention via planning and technical codes (Lowe, 2011). London also has an extensive history of leasehold provision of housing and high-density development but has only recently experienced a heightened increase in private rental apartment development (Craggs, 2018). In the same period as Melbourne, London also experienced an increased period of apartment planning approvals and construction with pressure to bring high numbers of private rentals onto the market (Booth, 2017). The two examples have a substantial degree of policy transfer in both directions (Gurran and Whitehead, 2011), and similar pressures on the private rental market in apartments due to economic and housing affordability tensions but in different regulatory contexts (Austin et al., 2014). As such, this reflection offers insight into the contrasting efforts towards regulation and government intervention internationally, and subsequent prospects for design regulation to lead to improved energy sustainability and equity.

This research focused on regulations relating to orientation in the housing design regulation applicable to each study site, the Australian National Construction Code (NCC) and London's Housing Supplementary Planning Guide (LHSPG). As outlined earlier in this article, orientation is critical to the energy sustainability of the apartment due to excessive solar heat gain and light gain. When a window, as a poor insulating material relative to a solid wall, is placed on the side of a dwelling that is exposed to the greatest summer sun i.e., west, then the apartment has high reliance on artificial cooling. Alternatively, an apartment's energy sustainability is impacted by facing an orientation with inadequate solar gain, either south in the southern hemisphere or north in the northern. Passive energy design instead suggests that windows should be placed on the northern side in the southern hemisphere and south in the northern as this orientation offers satisfactory sun levels in winter, and these windows can be easily shaded to prevent overheating in summer. East facing windows are a permissible second-best option as they permit light from the cooler, morning part of the day. Dual aspect, where windows are placed on two sides of the dwelling, also helps control the temperature by allowing cross ventilation through the dwelling while offering multiple options for managing sunlight exposure.

Although regulations offer an effective tool to be able to manage energy sustainability, there is a need for greater empirical understanding of how regulation operates and in different situations. This research has only investigated the impact of orientation on apartments' energy sustainability due to the spatially dependent nature of this regulation and, therefore, applicability to the study focus. However, the findings of this research, highlight the need for further empirical research into energy sustainability in apartments and greater investigation of the various other design features, such as window height, wall material and colour choice and room air circulation, that contribute to energy sustainability and their corresponding regulation. Further understanding of other regulation modes and their ability to improve energy sustainability would also be beneficial. This greater understanding is significant for the future development of energy sustainable apartments and energy justice in cities.

\section{Empirical Observation of Design Patterns Still Permissible by the Regulations}

A pragmatic ontology privileges the truth that is physically realised. This pragmatism aligns with an empirical methodology by focusing on observation and experience to provide a greater understanding of the material reality (Biesta, 2010). This research empirically observed apartment buildings with planning approval whose designs were therefore permissible to be built. These designs highlight the design values deemed acceptable by that specific planning regulation. Repeating this process across multiple regulations provides an insight into the range of definition and approach of energy sustainability in housing design regulations. Healey (1993) proposed that content analysis of different planning documents using a communicative planning method can empirically reveal the definition of design quality valued by the stakeholders involved in the document's production. By comparing a topic between one plan to another, Healey proposed that it is possible to understand the range across which a planning document can define design quality. This comparison includes both those elements that were included and those that were not within the plan.

Healey's (1993) mode of content analysis limits the observation to only the language included within a design plan. Scholars have criticised the language used in design regulations as vague and subject to interpretation (Ben-Joseph, 2005; Carmona et al., 2010). This ambiguity of meaning could affect the functionality and agency of the regulation to underpin improved design quality. For example, different regulations may appear to include the same topic of quality at the language level, and yet the method used by each regulation to measure compliance may have a different, observable impact upon the level of quality the regulation detects and therefore deems just. The many criticisms of the language of regulation indicate that an analysis focused on this level alone would not capture the tool's full extent, their functions for design quality and the values agreed upon in the consultation process. Therefore, in addition to analysing how the design regulations define design quality, this research extends Healey's (1993) content analysis by observing the regulation's actual spatial design impact within the apartment plans to understand better the scope of design quality each regulation permitted as acceptable. 
In addition to noting the textual description of orientation requirements in the NCC and the LHSPG regulations, the researcher observed the measurement method outlined by each regulation and the design layout of orientation that remain permissible. The researcher notes each of the apartment orientations in the floor plate faces, and the corresponding size type of each apartment. They also record the proportions of orientations available across a floor plate, whether one orientation is not present or complemented by a dual aspect design. If the orientation is split over two orientations, i.e., northeast, the greatest orientation is observed and the researcher notes this detail on the results. Trends in the general design layout, location and size type of individual apartments were also observed as a supplementary context for each of the buildings studied. This observation also included applying each regulation to the buildings that originated in the opposite city to broaden the understanding of how each regulation operated.

The buildings to be studied were selected from an extensive list of buildings constructed between 2010 and 2015 compiled from local authority registrars of planning permission applications. This period saw an increase in apartment development in both Melbourne and London. The list was refined from over 100 entries per location down to $10-15$ buildings. This occurred via the definition of an apartment building as a building height above 4 levels and exclusively residential in use above the ground floor. Affordable apartment buildings were also selected, with affordable defined as rent equal to or $<30 \%$ of a household's disposable income (Yates, 2007). This was checked via a randomised sample of 10 apartment listings per building on an online real estate listing website at the time of selection. No other design elements were highlighted or excluded through this data refinement process. The similarities in design that occurred between the set enabled the research to observe industry practises around design quality in situations with tighter margins that force efficient design in each location. Building plan observations were conducted until data saturation was achieved, and no further new information was collected from additional buildings. This process resulted in a total of 18 buildings in Melbourne and 12 buildings in London studied.

The researcher conducted a desktop analysis using plans that have received planning approval. These plans enabled the researcher to mirror how the regulations would be used for the assessment of the planning permit and the level of information that was generally produced at this stage of the building process. Building plans also allowed the researcher to practically analyse many apartment buildings as onsite measurement would be time-consuming to organise and conduct. In Melbourne, the plans were provided either by the planning department for each local authority or the building's architect directly due to research permission requirements by one local authority. In London, the building plans were downloaded directly from the local authority's website. The researcher also supplemented the desktop analysis of the building plans with site visits to each apartment building. While it was not possible to arrange access internally to the apartments studied, the general character, proportions of the building and location from external observations added further richness to the study (Wheeler, 2004).

\section{SPATIAL OBSERVATIONS OF APARTMENT DESIGNS BUILT UNDER THE DIFFERENT ENERGY SUSTAINABILITY REGULATIONS}

The spatial observation of apartment designs, size-types and orientation across multiple apartment buildings revealed permissible design patterns in each regulation. All of the Melbourne buildings studied utilised a double-loaded corridor layout without preselection, where apartments are accessed from an internal central corridor and fan outwards in all directions. This industry practise of design layout maximises the yield of apartments possible for the site but results in floor plates of the buildings composed of apartments facing all orientations. These orientations remained permitted by the regulation. Predominantly these apartments were single-aspect, in that they only had windows on one orientation which is problematic for energy sustainability if the apartment faces a poor ordination with no alternative available. The NCC also permitted single-aspect apartments to face any orientation. While the building as a whole may be compliant with the energy sustainability regulations, the individual apartments with their different orientations in the floorplate have differing levels of design quality.

Within these floor plates, there were distinctive patterns in the orientation design of the different apartment size-types, either 1-bedroom or 2-bedroom apartments (see Table 1). Firstly, the researcher observed that there was not an exclusive allocation of a specific orientation to either bedroom size-type. At just over a third, a comparatively small proportion of the Melbourne buildings had all of the 1-bedroom apartments on a floor plate exclusively of poor quality of orientation and facing exclusively south with insufficient light levels. A similar minority of the buildings had all of the 2-bedroom apartments on the floor plate only with high-quality orientation in that they either face north or were dual access. No buildings had the opposite, with 1-bedroom apartments with only high-quality orientation and 2-bedrooms with only poor-quality orientation.

Instead, the results showed that different quality levels in orientation were available in both apartment size types across most of the buildings. This result indicates that a choice in quality level existed for all apartment sizes in Melbourne. The existence of some exclusivity, however, importantly highlights that the Australian regulations permit this exclusivity and offer no protection to the apartment resident.

While the researcher did not observe a significant exclusivity in size to quality level, they observed that the 2-bedroom sized apartments predominantly occupied the better performing orientations in the Melbourne buildings, and the 1-bedroom apartments mainly occupied the lower quality orientation. Predominately, in this instance, was defined as $65 \%$ or more of each apartment size type present on the floor plate. Eight out of the eighteen buildings had 2-bedroom apartments located mainly with the best orientation, and nine buildings had 2-bedroom apartments predominantly in the medium orientations in the floor plate. Only one building placed a 2-bedroom apartment in the poor-quality orientation of south. The majority of 1 
TABLE 1 | Percentage of Melbourne's apartment size types that fill each orientation.

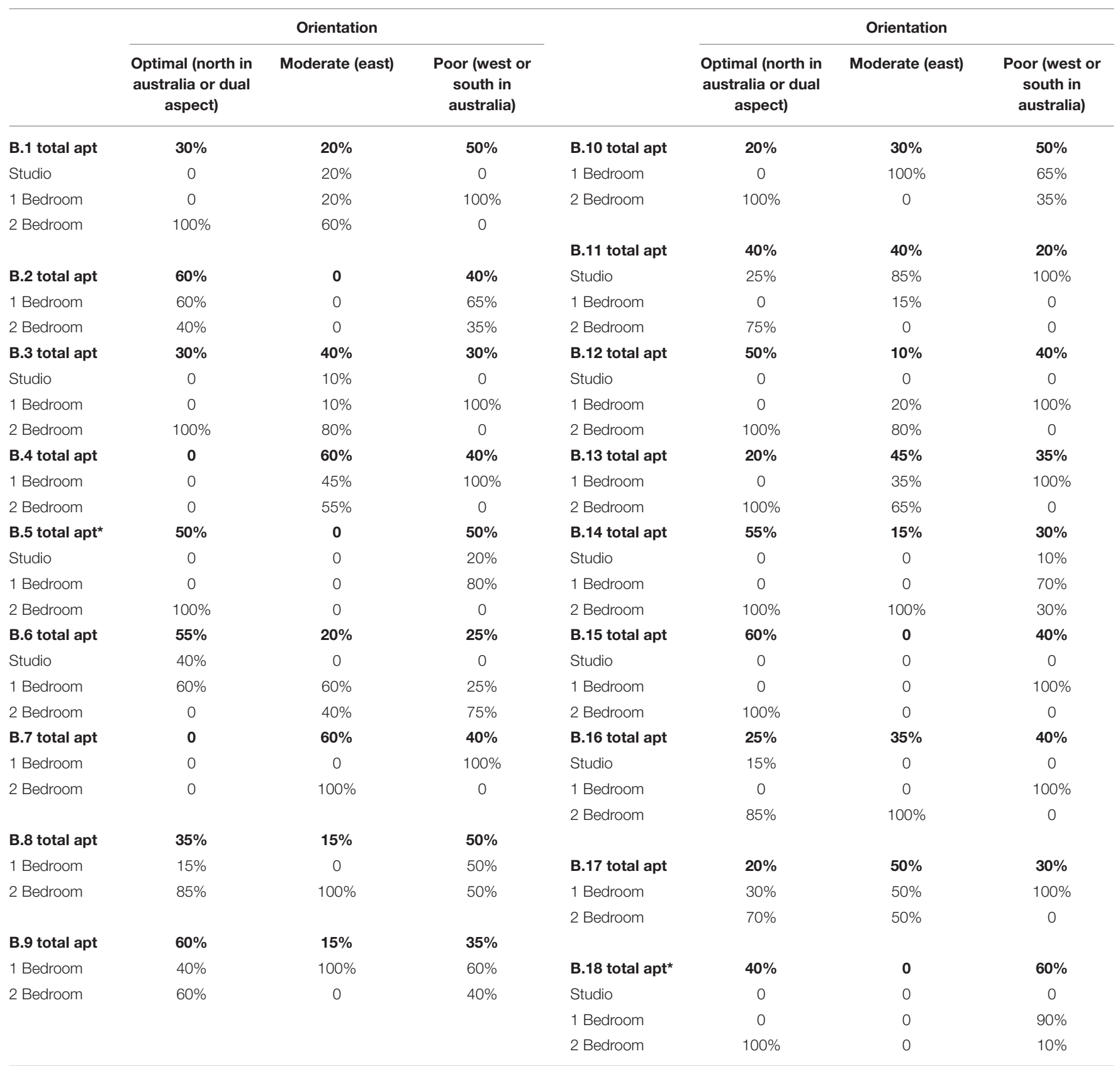

${ }^{*}$ Denotes the apartments whose orientation was split over two sides, B.5 slightly orientated towards northeast and B.18 slightly towards northwest.

bedroom and studio apartments, conversely, fulfilled the more inferior quality locations available to complete the floor plate, with a higher proportion of thirteen out of the eighteen buildings locating 1-bedroom apartments in the poor orientation quality location and five having a mixture between the medium to poor quality locations. No studio or 1-bedroom sized apartments were predominately located in their building floor plate's best orientation location.

Alternatively, all except one building in the London set complied with the LHSPG requirement to avoid the poor orientation levels completely within the building. While dual loaded corridors were still common, 11 of the 12 buildings, if one of the apartment's studied from London faced a poor orientation, the apartment was supplemented by a secondary aspect (see Table 2). This dual aspect apartment offers more sunlight control and cross-ventilation for the resident. There was no pattern in apartment size type for those that were dual aspect. This regulation mode did not result in all buildings using the best orientation only or being an exemplar of energy sustainability. However, it did establish 
TABLE 2 | Percentage of London's apartments that fill each orientation.

\begin{tabular}{|c|c|c|c|c|c|c|c|c|c|}
\hline & \multicolumn{4}{|c|}{ Orientation } & & \multicolumn{4}{|c|}{ Orientation } \\
\hline & $\begin{array}{l}\text { Optimal (south in } \\
\text { london) }\end{array}$ & $\begin{array}{c}\text { Moderate } \\
\text { (east) }\end{array}$ & $\begin{array}{c}\text { Poor (west or } \\
\text { north in london) }\end{array}$ & Dual & & $\begin{array}{l}\text { Optimal (south in } \\
\text { london) }\end{array}$ & $\begin{array}{c}\text { Moderate } \\
\text { (east) }\end{array}$ & $\begin{array}{l}\text { Poor (west or } \\
\text { north in london) }\end{array}$ & Dual \\
\hline LB.1 total apt & $20 \%$ & $50 \%$ & 0 & $40 \%$ & LB.7 total apt & $10 \%$ & $30 \%$ & 0 & $60 \%$ \\
\hline LB.2 total apt & $30 \%$ & $20 \%$ & 0 & $40 \%$ & LB.8 total apt & $40 \%$ & $30 \%$ & 0 & $30 \%$ \\
\hline LB.3 total apt & $30 \%$ & $30 \%$ & 0 & $40 \%$ & LB.9 total apt & 0 & $0 \%$ & 0 & $100 \%$ \\
\hline LB.4 total apt & 0 & $20 \%$ & 0 & $80 \%$ & LB.10 total apt & 0 & $10 \%$ & 0 & $90 \%$ \\
\hline LB.5 total apt & 0 & 0 & 0 & $100 \%$ & LB.11 total apt & $50 \%$ & 0 & $30 \%$ & $30 \%$ \\
\hline LB.6 total apt & $20 \%$ & $30 \%$ & 0 & $50 \%$ & LB.12 total apt & $20 \%$ & $50 \%$ & 0 & $30 \%$ \\
\hline
\end{tabular}

that the minimum acceptable level of quality is avoiding the worst orientation.

None of the Melbourne apartment buildings complied with the LHSPG requirement, with all having at least one individual apartment with singular aspect of a poor orientation of south or west. Two buildings, however, avoid west-facing apartments. One building achieves this by including a short section of single loaded corridor that enables those facing a poor orientation to be dual aspect and the other by orientating the building away from a shared wall with the neighbouring building.

\section{HOW REGULATION SCALE AFFECTS THE ENERGY JUSTICE ACHIEVED IN APARTMENT BUILDINGS}

Energy justice's focus on equity at the scale of the resident offers a lens to evaluate the significance of scale within housing design regulations in apartment buildings (Henning, 2020). The NCC regulates the energy performance of new buildings at a whole building scale to provide protection for the externality of climate change, as well as the energy vulnerability of residents with passive design minimising artificial energy use. Defining compliance at the whole building scale sufficiently protects residents in detached housing as the resident occupies the building regulated entirely.

However, this research found that when this whole building scale was applied to an apartment building, the regulation offered little energy vulnerability protection to the residents. The NCC and regulation in general that uses the whole building scale fails to acknowledge that apartment buildings comprise of individual dwellings with separate residents within the entire building envelope. Unlike detached housing, each apartment's energy sustainability can vary relative to the building's sustainability taken as a whole. The orientation and, therefore, energy sustainability of the separate apartments can vary within the floor plate greatly. As long as the whole building complied, the research found that the NCC permitted apartments to face all orientations. Within the studied Australian apartment buildings, a majority of individual apartments were found to face south or west with substandard sun exposure or north, which in the Australian context is a more temperate orientation. The residents whose apartments face south or west were unjustly burdened by regular reliance on artificial heating, cooling and lighting to manage this poor-quality orientation comfortably. Therefore, measurement at the whole building scale permits inequity as floor plates in the Australian apartment buildings studied were composed of a series of higher than average performing apartments whose gains were offset by other poor performing apartments.

Housing design regulation that defined energy sustainability at the individual apartment scale, by comparison, provided greater protection from the worst orientation and, therefore, the individual resident. The LHSPG regulated against single aspect apartments being located in the North orientation that, in the Northern Hemisphere, received insufficient radiant heat and warmth in winter and a west orientation to avoid overheating in the summer afternoon. As a consequence of the regulations being defined at this resident scale, the worst orientations possible within the floor plate were not filled by apartments, but either subtracted from the floor plate or utilised for services. Apartments were only located on the better orientations. The LHSPG, therefore, establishes a minimum base level for orientation that is accepted through the regulation scale and improves the passive design of apartment buildings for every resident. This scale also ensures that one apartment is not able to compensate for the energy sustainability of another, and the whole building is the sum of the worst-performing apartment or better.

Therefore, this research builds upon the call by Daniel et al. (2020) for greater regulation into energy sustainable housing design by highlighting the significance of scale in housing design regulation for apartment building types. By focusing on the resident, energy justice reveals the inequities occurring with regulation requirements defined at the whole building scale in apartments and the need to expand and apply regulation compliance to the residents' apartment level if the regulation is to help alleviate energy vulnerability. This research has shown that justice is misconstrued when an apartment building's energy sustainability is observed at the inappropriate scale of the whole building. This practise masks the poor performance of some apartments and the inequity in the whole building outcome. The ability of the resident scale within apartment design regulation to improve housing design quality is also recognised in the new planning housing design regulations for Victoria, Australia (within which Melbourne is located); the Better Apartment Design Standards (2016, 2016). The energy sustainability requirement within this regulation stipulates a minimum performance level for each apartment in the building 
to mitigate the national NCC regulation's shortcoming being defined at the whole building scale. This inclusion in an apartment specific regulation further supports the findings of this research regarding the significance of regulation to recognise the resident scale present in apartments buildings, but not as necessary for detached housing.

Research has shown that renters and those renting apartments are the most at risk demographic within Australia to experience energy vulnerability (Australian Council of Social Services, 2017; Poruschi and Ambrey, 2018). This research also contributes new evidence of the externality of renters in apartment buildings and the consequent need for energy sustainability regulation in apartment buildings. In Melbourne, studio and one-bedroom size type apartments are almost exclusively rental properties making up 91 and $80 \%$, respectively, of the existing stock. More of the large apartment size types (i.e., 2-bedroom and above) are owner-occupied (ABS, 2018). The NCC regulation did not place restrictions on which size type of apartment could be located in the good or poor orientation locations, nor the proportions of these types in these areas. Although it was permissible within the NCC regulation to exclusively situate one particular type in the poor orientations, market logic did offer a degree of guidance in this case as many buildings studied elected not to undertake this exclusively. Instead, the majority (over $80 \%$ ) of the poor orientation was filled with the 1-bedroom apartment size types while the larger, 2-bedroom types occupied a majority of the best orientation. However, multiple Melbourne buildings did ignore these market patterns and exclusively filled the poor orientation locations with studio and 1-bedroom size-type apartments. As a result, this research has shown that rental properties occupy a majority of the poor orientation locations and apartments with poor energy sustainability and that renters are disproportionately affected by the insufficient regulation protection offered when energy sustainability compliance is measured at the whole building level.

The pervasiveness of this market pattern, that rental properties occupy a majority of poor orientation locations, highlights how impeded residents of rental properties are in demanding better energy performing apartments through the market. As highlighted by Liu and Judd (2018), split incentives remove any incentive or consequence for investors or landlords to select more than the worst-performing orientation for their tenants as it is the tenants, not the investor, who manages the unacceptably high running costs of the investors' selection. Conversely, the financial windfalls of a better performing apartment in this rental context bring no benefit to the investor, who have little trouble attracting tenants with the low rental vacancy rates in Australia. Owner occupiers' value and therefore create market demand for better-orientated apartments that developers respond to. By comparison, the investor has little incentive or consequence to demand better quality for their tenant than these poor energy-performing apartments, and renters lack agency to demand more from their landlords. Due to these structural barriers within the rental sector, this research has demonstrated the energy injustice occurring in rentals in Australian apartment buildings and how renters are disproportionately and unjustly burdened with poor orientation and regular reliance on artificial heating, cooling and lighting to live comfortably. This evidence of the externality of renters within the apartment housing market provides further justification for energy sustainable regulation at the resident scale and the need to establish a minimum acceptable level of energy sustainable quality across all apartments, regardless of size or, by association, tenure type. Building upon recent evidence of the need for greater energy sustainability protection via regulation in rental properties (Daniel et al., 2021), this research demonstrates the significance of the scale of the regulation requirements within apartment buildings. Specifically, it has argued the importance of individual resident scale in apartment design regulation for rental properties whose residents have little agency in a low vacancy rental market.

\section{CONCLUSION}

To conclude, this research demonstrates the significance of scale in housing design regulation on energy sustainability, focusing on the application in apartment buildings. It outlines how building scale can impact the degree of protection the regulation offers residents from energy vulnerability and the energy justice achieved by the planning control overall. In addition to protecting climate change at the scale of the whole building, this research found significant need for regulation to recognise and provide protection at the resident's experience scale within apartment buildings. This scale defines compliance at the individual apartment scale, recognising every apartment within a building to achieve a minimum level of energy sustainability throughout. When regulation compliance is defined at the whole building scale, this research highlighted how one apartment's above-average performance can compensate or mask the more unsatisfactory performance of another but still comply overall. This regulation compliance scale produces inequity across the building in general, but specifically, this article also showed that these poor orientations were predominantly filled by 1-bedroom apartments targeted at the rental market. This finding further justifies the need for resident scale energy sustainability regulation, especially with the rental market growth in Australia's apartments and the limited agency renters have to demand quality in a competitive market. When focused on the resident scale, housing design regulation offers a vital planning tool to extend energy sustainability beyond climate mitigation and ensure a more just energy sustainability in apartments.

\section{DATA AVAILABILITY STATEMENT}

The raw data supporting the conclusions of this article will be made available by the authors, without undue reservation.

\section{AUTHOR CONTRIBUTIONS}

The author confirms being the sole contributor of this work and has approved it for publication. 


\section{FUNDING}

This research data was collected as part of the author's Ph.D. for the ARC linkage project, Project HOME (LP150100089). This research was supported by the AHURI Ph.D. Top-up scholarship program.

\section{REFERENCES}

ABCB (2020). BCA History | Australian Building Codes Board. Available online at: https://ncc.abcb.gov.au/ncc-online/About/BCA-History

ABS (2017a). Consumer Price Index: Dec 2016-2017. Canberra, ACT: ABS.

ABS (2017b). Greater Melbourne (GCCSA). Available online at: https://bit.ly/ $2 \mathrm{y} 1 \mathrm{EK} 38$

ABS (2018). 2016 Census - Counting Dwellings, Place of Enumeration (MB), STRD Dwelling Structure and BEDRD Number of Bedrooms in Private Dwelling (Ranges) by TEND Tenure Type by GCCSA. Canberra, ACT: ABS.

ABS (2019). Building Approvals, Cat.No. (8731).0. Available online at: https://www. abs.gov.au/ausstats/abs@.nsf/mf/8731.0

ARK resources (2016). Better Apartments Discussion Paper: Apartment Energy Metrics. Melbourne, VIC: ARK Resources.

Austin, P., Gurran, N., and Whitehead, C. (2014). Planning and affordable housing in Australia, New Zealand and England: common culture; different mechanisms. J. Hous. Built Environ. 29, 455-472. doi: 10.1007/s10901-013-9356-3

Australian Building Codes Board (2019). National Construction Code. Vol. 1. Canberra, ACT: Australian Building Codes Board.

Australian Bureau of Statistics (2016a). 2006-2016 Census QuickStats: Australia. Available online at: https:/quickstats.censusdata.abs.gov.au/census_services/ getproduct/census/2016/quickstat/036?opendocument

Australian Bureau of Statistics (2016b). 2006-2016 Census: STRD Dwelling Structure by TEND Tenure Type: Australia. Available online at: https://auth. censusdata.abs.gov.au/webapi/jsf/tableView/tableView.xhtml

Australian Council of Social Services, Brotherhood of St. Laurence, and The Climate Institute. (2017). Empowering Disadvantaged Households to Access Affordable, Clean Energy. Melbourne, VIC: ACOSS. Available online at: https://www.acoss.org.au/wp-content/uploads/2017/07/ACOSS_ BSL_TCI_Empowering-households.pdf

Azpitarte, F., Johnson, V., and Sullivan, D. (2015). Fuel Poverty, Household Income and Energy Spending: An Empirical Analysis for Australia Using HILDA Data. Melbourne, VIC: Brotherhood of St. Laurence.

Bagshaw, E. (2018). Electricity Prices Jump 12 per Cent, Six Times the Average Pay Rise. The Sydney Morning Herald. Available online at: https://www.smh.com. $\mathrm{au} /$ business/the-economy/electricity-prices-jump-12-per-cent-six-times- theaverage-pay-rise-20180131-p4yz4k.html (accessed January 31, 2018).

Baker, E., Daniel, L., Bentley, R., Pawson, H., Stone, W., Beer, A., et al. (2018). The Australian Housing Conditions: Technical Report. Adelaide, SA: The University of Adelaide.

Ben-Joseph, E. (2005). The Code of the City: Standards and the Hidden Language of Place Making. Cambridge, MA: MIT Press.

Berry, M. (2014). Neoliberalism and the City: or the failure of market fundamentalism. Hous. Theory Soc. 31, 1-18. doi: 10.1080/14036096.2013.839365

Biesta, G. (2010). "Pragmatism and the Philosophical Foundations of Mixed Methods Research1," in SAGE Handbook of Mixed Methods in Social \& Behavioral Research, eds A. Tashakkori and C. Teddlie(California, CA: SAGE Publications, Inc.), 95-118.

Booth, P. (1996). Controlling Development: Certainty and Discretion in Europe, the USA and Hong Kong. London: Routledge.

Booth, R. (2017). Sadiq Khan: London Needs to Build 66,000 New Homes a Year, up from 29,000. The Guardian. Available online at: http://www. theguardian.com/uk-news/2017/oct/27/sadiq-khan-to-raise-target-foraffordable-housing-in-london (accessed October 27, 2017).

Carmona, M., Tiesdell, S., Heath, T., and Oc, T. (2010). Public Places, Urban Spaces: The Dimensions of Urban Design. 2nd Edn. Oxford: Elsevier.

\section{ACKNOWLEDGMENTS}

The author would like to thank Dr. Mette Hotker for her advice and guidance in the writing of this article. Thanks also to the reviewers whose thoughtful comments were very helped to refine my thinking.

CoreLogic (2016). The Profile of the Australian Residential Property Investor Available online at: https://www.corelogic.com.au/resources/pdf/reports/ CoreLogic\%20Investor\%20Report_June\%202016.pdf

Craggs, D. (2018). Skyscraper development and the dynamics of crisis: the new London skyline and spatial recapitalization. Built Environ. 43, 500-219. doi: 10.2148 /benv.43.4.500

D’Ambrosio, L. (2020). Helping Victorians Pay Their Power Bills. State Government of Victoria. Available online at: https://www.premier.vic.gov.au/helpingvictorians-pay-their-power-bills.

Daniel, L., Baker, E., Beer, A., and Thien Anh Pham, N. (2021). Cold housing: evidence, risk and vulnerability. Hous. Stud. 36, 110-130. doi: 10.1080/02673037.2019.1686130

Daniel, L., Moore, T., Baker, E., Beer, A., Willand, N., Horne, R. et al. (2020). Warm, Cool and Energy-Affordable Housing Policy Solutions for Low-Income Renters. AHURI Final Report, no. 338.

DELWP (Department of Environment Land Water and Planning) (2016). Better Apartments: Design Standards. Melbourne: The State of Victoria.

Department of Environment Land Water and Planning (2015). Better Apartments: A Discussion Paper. Melbourne, VIC: The State of Victoria.

Dow, A. (2015). How Money Is Shaping Melbourne's “Generic" Apartments. The Age. Available online at: https://www.theage.com.au/national/victoria/howmoney-is-shaping-melbournes-generic-apartments-20150807-giu8vd.html (accessed August 9, 2015).

Easthope, H., Crommelin, L., Troy, L., Davison, G., Nethercote, M., Foster, S., et al. (2020). Improving Outcomes for Apartment Residents and Neighbourhoods. AHURI Final Report, no. 329.

Freestone, R. (2012). “A Historical Perspective," in Planning Australia: An Overview of Urban and Regional Planning, eds S. Thompson and P. Maginn (Cambridge: Cambridge University Press), 73-97.

Giles-Corti, B., Kleeman, A., and Foster, S. (2015). Better Apartments Health and Wellbeing Study. Melbourne, VIC: The University of Melbourne.

Glossop (2015). Better Apartments Stakeholder Engagement Workshop Report. Melbourne. VIC: DELWP.

Gurran, N., and Whitehead, C. (2011). Planning and affordable housing in australia and the UK: a comparative perspective. Hous. Stud. 26, 1193-1214. doi: 10.1080/02673037.2011.618982

Healey, P. (1993). "Planning through debate: the communicative turn in planning theory," in The Argumentative Turn in Policy Analysis and Planning, eds F. Fischer and F. Forester (London: University College London), 233-253. doi: 10.1215/9780822381815-011

Heffernan, E., Beazley, S., McCarthy, T., and Imroz Sohel, M. (2017). Energy efficiency within mid-rise residential buildings: a critical review of regulations in Australia. Energy Proc. 121, 292-299. doi: 10.1016/j.egypro.2017.08.030

Henning, A. (2020). Recognizing energy dilemmas and injustices: an interview study of thermal comfort. Sustainability 12:4703. doi: 10.3390/su121 14703

Horne, R. (2006). "International assessment of the environmental performance of housing, and prospects for sustainable citie," in The Sustainable City IV: Urban Regeneration and Sustainability (Tallin: WIT Press), 29-38. doi: 10.2495/SC060031

Hulse, K., and Yates, J. (2016). A private rental sector paradox unpacking the effects of urban restructuring on housing market dynamics. Hous. Stud. 32, 253-270. doi: 10.1080/02673037.2016.1194378

Hutchens, G. (2020). Coronavirus has hit australia's job market harder than unemployment figures suggest. $A B C$. Available online at: https://www.abc. net.au/news/2020-05-14/coronavirus-australia-job-market-unemploymentfigures-april/12247990 (accessed May 14, 2020).

IEA (2015). Energy Statistics of OECD Countries 2015. Paris: OECD Publishing. 
Islar, M., Brogaard, S., and Lemberg-Pedersen, M. (2017). Feasibility of energy justice: exploring national and local efforts for energy development in nepal. Energy Policy 105, 668-676. doi: 10.1016/j.enpol.2017. 03.004

Kohler, M., and Van Der Merwe, M. (2015). Long-Run Trends in Housing Price Growth. RBA Bulletin. p. 15.

Land Registry (2020). UK House Price Index. Available online at: https:// landregistry.data.gov.uk/app/ukhpi

Liddell, C., and Guiney, C. (2015). Living in a cold and damp home: frameworks for understanding impacts on mental well-being. Public Health 129, 191-199. doi: 10.1016/j.puhe.2014.11.007

Liu, E., and Judd, B. (2018). Tenure as Barrier to Low Carbon Living. Adelaide, SA: State of Australian Cities.

Lowe, S. (2011). The Housing Debate. Bristol: The Policy press.

Marsh, A., and Gibb, K. (2011). Uncertainty expectations and behavioural aspects of housing market choices. Hous. Theory Soc. 28, 215-235. doi: 10.1080/14036096.2011.599182

Mayor of London (2016). Housing: Supplimentary Planning Guidance. London: Greater London Authority.

McCauley, D. (2018). Energy Justice: Re-Balancing the Trilemma of Security, Poverty and Climate Change. Cham: Springer International Publishing.

Moore, T., and Holdsworth, S. (2019). "The built environment and energy efficiency in australia: current state of play and where to next," in Energy Performance in the Australian Built Environment, eds R. Priyadarsini, M. Andamon, and T. Moore (Singapore: Green Energy and Technology; Springer), 45-59. doi: 10.1007/978-981-10-7880-4_4

Moore, T., Horne, R., Martel, A., London, G., and Alves, T. (2014). "Valuing Form and Function: Perspectives from Practitioners about the Costs and Benefits of Good Apartment Design," in 7th Urban Design Conference (Adelaide, SA).

Oxley, M. (2004). Economics, Planning and Housing. Hampshire: Palgrave MacMillian.

Parkinson, S., Rowley, S., Stone, W., James, A., Spinney, A., and Reynolds, M. (2019). Young Australians and the Housing Aspirations Gap. AHURI Final Report, no. 318.

Pears, A. (2020). Renters in Victoria Soon Won't Have to Deal with Dodgy Heaters and Insulation. Now Other States Must Get Energy-Efficient. The Conversation. Available online at: http://theconversation.com/renters-in-victoria-soonwont-have-to-deal-with-dodgy-heaters-and-insulation-now-other-statesmust-get-energy-efficient- 150358

Poor, J. A., Thorpe, D., and Goh, Y. (2018). The key-components of sustainable housing design for Australian small size housing. Int. J. GEOMATE 15, 23-29. doi: $10.21660 / 2018.49 .3583$

Poruschi, L., and Ambrey, C. (2018). Densification, what does it mean for fuel poverty and energy justice? An empirical analysis. Energy Policy 117, 208-217. doi: 10.1016/j.enpol.2018.03.003
Potter, B., and Tillet, A. (2017). Australian Households Pay Highest Power Prices in World. Australian Financial Review. Available online at: https://www.afr. com/politics/australian-households-pay-highest-power-prices-in-world20170804-gxp58a (accessed August 4, 2017).

Prasad, S. (2004). "Inclusive Maps," in Designing Better Buildings, eds S. MacMillan (London: Spon Press), 175-184.

Rickwood, P., Glazebrook, G., and Searle, G. (2008). Urban structure and energyA review. Urban Policy Res. 26, 57-81. doi: 10.1080/08111140701629886

Simcock, N., and Mullen, C. (2016). Energy demand for everyday mobility and domestic life: exploring the justice implications. Energy Res. Soc. Sci. 18, 1-6. doi: 10.1016/j.erss.2016.05.019

Simmons, R. (2008). Good Design: The Fundamentals. London: CABE Commission for Architecture and the Built Environment.

Sovacool, B., and Dworkin, D. (2015). Energy justice: conceptual insights and practical applications. Appl. Energy 142, 435-444. doi: 10.1016/j.apenergy.2015.01.002

Sovacool, B., Sidortsov, R., and Jones, B. (2014). Energy Security, Equality and Justice. London: Taylor \& Francis Group.

Thomson, H., Snell, C., and Bouzarovski, S. (2017). Health, well-being and energy poverty in europe: a comparative study of 32 European Countries. Int. J. Environ. Res. Public Health 14:584. doi: 10.3390/ijerph14060584

Tiesdall, S., and Allmendinger, P. (2008). "Planning tools and markets: towards an extended conceptualisation," in Planning Tools and Markets: Towards an Extended Conceptualisation, eds D. Adams, C. Watkins, and M. White (Williston, ND: Wiley), 56-76. doi: 10.1002/9780470757789.ch4

Walker, G., and Day, R. (2012). Fuel poverty as injustice: integrating distribution, recognition and procedure in the struggle for affordable warmth. Energy Policy 49, 69-75. doi: 10.1016/j.enpol.2012.01.044

Wheeler, P. (2004). "Housing quality indicators in practice," in Designing Better Buildings, eds S. MacMillan (London: Spon Press), 206-15.

Yates, J. (2007). Housing Affordability and Financial Stress. Research Paper 6. Sydney: Australian Housing and Urban Research Institute.

Yin, R. (2014). Case Study Research: Design and Methods. 5th Edn. California, CA: Sage.

Conflict of Interest: The author declares that the research was conducted in the absence of any commercial or financial relationships that could be construed as a potential conflict of interest.

Copyright (c) 2021 Gower. This is an open-access article distributed under the terms of the Creative Commons Attribution License (CC BY). The use, distribution or reproduction in other forums is permitted, provided the original author(s) and the copyright owner(s) are credited and that the original publication in this journal is cited, in accordance with accepted academic practice. No use, distribution or reproduction is permitted which does not comply with these terms. 